\title{
Sexualidades, esportes e Teoria Queer: inter-relações
}

\author{
Sport, Sexualities and Queer/ \\ Theory.
}

CAUDWELL, Jayne (Org.).

London/New York: Routledge, 2006. 180

p.

Sport, Sexualities and Queer/Theory é uma coletânea de 10 artigos organizada por Jayne Caudwell, uma pesquisadora sênior em Sociologia do Esporte e Culturas do Lazer, da Universidade de Brighton, Inglaterra. O livro foi publicado em 2006, simultaneamente em Londres, Nova lorque e no Canadá, pela editora Routledge e contém artigos científicos europeus e norteamericanos, além de uma modesta participação australiana.

No prefácio, os editores, Jennifer Hargreaves e lan McDonald, ressaltam que é a primeira antologia publicada sobre gênero, sexualidade, queer e Teoria Queer e sua interrelação com o esporte. Além disso, destacam que se pretende uma referência a tais estudos no que se pode designar como uma 'sociologia do esporte queer', a qual se lançará, de maneiras particulares, à compreensão de como a sexualidade é experimentada, representada e negociada em diferentes contextos esportivos.

Na introdução, Caudwell, como organizadora da coletânea, situa os leitores e problematiza os conceitos a serem empregados ao longo do livro. O próprio conceito queer, já mencionado, parte de uma identidade política de lésbicas e gays e caminha em direção a uma "política da diferença, da resistência e do desafio". Destaca que os autores utilizarão variadas definições para identificar a "Teoria Queer': ora "estudos queer", ou "políticas queer" e mesmo "teorias queer", no plural.

O livro, assim, está dividido em três partes principais, detalhadas a seguir. A primeira parte intitulada "O Queer e a Teoria Queer nos estudos do esporte" compõe-se de dois capítulos, que se encarregam de refletir sobre o universo queer no campo esportivo.

No capítulo 1, “'Queerizando’ teorias de sexualidade nos estudos sobre esporte", Heather Sykes apresenta um mapeamento da Teoria Queer nas últimas duas décadas e analisa contribuições teóricas sobre o queer por parte de alguns teóricos. A autora ressalta ser difícil estabelecer uma versão simplificada da Teoria Queer justamente por seu caráter plural e multifocado, sublinhando que pretende mostrar "como a crítica da Teoria Queer sobre a identidade sexual, e as suspeitas pós-modernas [...] poderão alterar a maneira como pensamos a sexualidade, o desejo e o corpo nos estudos esportivos" (p. 13). Destaca a constituição de uma "teoria trans", devido à popularização de análises científicas sobre o "corpo intersexo", e sublinha, por fim, as contribuições das subjetivações de Michel Foucault (1985), das performatividades de Judith Butler (2004) e do legado da psicanálise.

Em "Além da conta: a branqueza nos estudos esportivos e o conhecimento queer", 2 Mary McDonald dedica boa parte do capítulo 2 criticando as publicações da área de estudos gays e lésbicos que não levam em conta a raça e, na grande maioria, produzem pesquisas sobre populações e grupos brancos. Chama, assim, explicitamente a atenção para essa "branqueza" nos estudos queer e para o fato que de isso já "passa da conta", pois não há praticamente produção alguma sobre indígenas, negros, amarelos, dentre outros grupos. Sugere uma 'desidentificação' de minorias queers assujeitadas a fim de promover resistência e confrontação aos padrões brancos de identificação dominantes.

Já a segunda parte, "Práticas esportivas e comunidades: desestabilizando a heteronormatividade?", traz quatro capítulos que pretendem analisar os efeitos do desdobramento da Teoria Queer em pesquisas realizadas no esporte.

Assim, em "Atletas queer e o processo de 'queerizar' o esporte", do capítulo 3, Heidi Eng foca-se em atletas norueguesas lésbicas e gays. A autora compara as diferentes condições de experiências no explicitar a sexualidade, em contextos esportivos, tanto de atletas mulheres 
quanto de homens. Além disso, Eng também tece considerações sobre os espaços sociais do esporte e a chamada "cultura do vestiário". ${ }^{3}$ Nesse sentido, toma emprestado de Foucault a análise dos múltiplos silêncios que são parte integral das estratégias que subjazem e permitem os discursos. A autora é a única, em toda a coletânea, que salienta explicitamente a questão da importância em "queerizar" o esporte por parte da população LGBT, ou seja, utilizar-se do esporte como forma de subversão dos jogos (in)visíveis da dominação heteronormativa imposta.

No capítulo 4, "Dez homens 'out': masculinidades esportivas gay no softbol", ${ }^{4}$ Nigel Jarvis apresenta sua pesquisa etnográfica sobre masculinidades (subordinadas) de homens gays no softbol. $O$ autor quer identificar se as práticas das equipes são atos de resistência queer ou apenas atos reprodutivos dentro de uma masculinidade hegemônica. Em oposição ao capítulo anterior sobre os atletas noruegueses no esporte de alto rendimento, neste capítulo a linguagem e o comportamento dos entrevistados aparecem generificados e sexualizados, ou seja, os atletas masculinos articulam coerentemente a sexualidade gay para Jarvis, pois seus discursos constantemente desafiam a "generificação" e a "sexização" da heteronormatividade discursiva do esporte de competição, apontando para a referência a atos sexuais e desejos gays, identidades sexuais gays e identidades de gênero. Contudo, o autor mostra que, apesar dessas expressões comportamentais e lingüísticas transgressivas, o comportamento de alguns jogadores reproduz as ações convencionais do esporte dominante, notadamente as condutas relacionadas à vitória. Assim, Jarvis conclui seu artigo levantando o quanto é difícil para grupos subordinados desafiarem as práticas esportivas incrustadas nas normas heterossexuais.

Em "Explorando os limites do queer no esporte: homens gays jogando tênis", lan Wellard trata do surgimento de um clube de tênis exclusivo para gays, ao Sul da Inglaterra. A formação do clube - bem como de grupos esportivos semelhantes que são criados por minorias sexuais - tenta criar, segundo o autor, um 'porto seguro', livre das tradições e dos rituais heterossexistas. Utilizando o conceito de "atos queer" (de Butler), Wellard destaca algumas maneiras com que os jogadores de tênis desafiaram as práticas hegemônicas nesse esporte. Entretanto, o autor constata que talvez grande parte dos próprios gays esportistas prefira, como aparece em suas próprias palavras, "atos héteros" de conduta. A assimilação de padrões convencionais do que a 'sociedade' espera é menos 'complicado' e exige 'menos' de quem é alvo das considerações.

Fica claro, nesse sentido, que tanto Jarvis quanto Wellard são influenciados pelas considerações teóricas de Brian Pronger, ${ }^{5}$ importante teórico na área de masculinidades, gêneros e homossexualidades no contexto esportivo. Basta observarmos que em 7 dos 10 capítulos da coletânea encontramos a obra The Arena of Masculinity, listada nas referências bibliográficas, na qual o próprio Pronger sublinha: "Apesar de esta obra concentrar-se na experiência esportiva da homossexualidade, o objetivo dela é mais ambicioso: o esporte é um veículo de exploração do significado da homossexualidade e, além disso, de compreensão do sexo e do gênero como partes fundamentais de nossa cultura". ${ }^{\circ}$

No capítulo 6, "A necessidade da vergonha queer para $\circ$ orgulho gay: uma análise sobre os Gay Games", de Judy Davidson, há uma análise dos chamados Gay Games e os eventos culturais que os envolvem. O mote de seu trabalho, $O$ da necessidade de uma vergonha queer para a 'obtenção' de um orgulho gay, parte de uma pesquisa nos arquivos históricos dos jogos e de uma análise sobre o papel desempenhado pelo fundador desses jogos, Thomas Waddell. A autora centra a sua análise nos arquivos discursivos do orgulho gay e relata que a recusa imposta à denominação "olimpíadas" ou "jogos olímpicos" para o título dos jogos alimentou uma vergonha original que o orgulho gay encobriu com o tempo. O capítulo busca explicações do domínio psíquico de uma coletividade envolvida na realização dos jogos e suas interrelações com a esfera social em que atuam. Nesse sentido inter-relaciona aspectos singulares da psicanálise para detalhar $o$ entendimento de como a heteronormatividade, no limite, produz o orgulho gay.

Logo após este capítulo, temos a terceira e última parte do livro, "Possibilidades para corpos queer e identidades no esporte", compreendida de quatro capítulos.

Assim, Caroline Symmons e Denis Hemphill's no capítulo 7, "Transgêneros e esporte nos Gay Games", levantam dados de arquivos históricos e dos regulamentos internos de três versões dos jogos, os IV Gay Games, Nova lorque (1994), V Gay Games, Amsterdã (1998), e VI Gay Games, Sydney (2002), resgatando a "política de gênero" dos jogos em respeito à inclusão de atletas transgêneros. De acordo com os autores, a 
versão ocorrida de Nova lorque colocou-se como pioneira na inclusão daqueles e na estruturação das regras e dos procedimentos que facilitaram suas participações. Em Amsterdã (1998), apesar de já existir uma estrutura de regulamentação para esse segmento, houve uma burocracia médico-psicológica que deixou muitos participantes insatisfeitos. ${ }^{7}$ Os jogos de Sydney, por sua vez, foram os mais 'inclusivos', não só porque toda a "política de gênero" foi pensada e estruturada durante 18 meses, mas porque toda a comunidade LGBT na cidade era constantemente consultada.

Gareth Owen, em "Catching Crabs: corpos, emoções e identidades gays na canoagem de competição convencional", ${ }^{8}$ mantém o foco no corpo do atleta participante dos gay games. $\mathrm{O}$ autor argumenta que corpos e emoções são inseparáveis do entendimento de gênero e identidade sexual na canoagem de competição; faz isso com seu próprio corpo durante quase dois anos de total imersão na vida social do clube gay de canoagem, participando de avaliações, regatas e árduos treinamentos. ${ }^{9}$ Realizou $\circ$ que denomina "etnografia reflexiva ou emotiva": seu corpo torna-se um instrumento de coleta de dados ao vivenciar as situações e explora, a partir disso, as possibilidades dessa narrativa centrada no self.

No capítulo 9, "Femme fatale: (re)pensando a femi-nina", Jayne Caudwell muda o foco do que vinha sendo considerado até então e analisa a feminilidade de atletas lésbicas de uma equipe londrina de futebol. A autora coloca em questão, como ponto de partida, a aceitação tácita de que uma equipe lésbica de futebol, rompendo a sexualidade normativa e deslocando o regime da heterossexualidade compulsória, seria entendida como "queer". Caudwell salienta, ainda, que o foco na(s) feminilidade(s) problematiza as noções freqüentemente aceitas, pelo padrão normativo, das mulheresmasculinas-lésbicas associadas às comunidades futebolísticas, como é destacado na literatura. Assim, a partir das tensões estabelecidas, o capítulo se finda com a proposição de novas reflexões teóricas para uma (re)leitura dessa(s) feminilidade(s) como potencial(is) subversiva(s) e com poder político capaz de desestabilizar as relações hegemônicas na formação da heteronormatividade.

Rebecca Lock, em "Heterossexualidade feminina: o processo doloroso da subjetivação", último capítulo da coletânea, sublinha a relação entre dor e feminilidade heterossexual no contexto esportivo do ice hockey feminino. A autora parte da argumentação de que a heterossexualidade e a dor são tomadas mais como fenômenos naturais do que discursivamente construídos. Ela detalhará, então, uma análise crítica de como os discursos que permeiam a dor do estupro, a dor do nascimento e a dor a ser medicalizada (no caso de mulheres requisitantes) criam uma "gramática generificada de violência". Lock pretende mostrar como a regulamentação das situações de exposição à dor no ice hockey funciona, indubitavelmente, para materializar atletas como sujeitos heterossexualmente femininos. Conclui, portanto, que dor e heterossexualidade são socialmente construídas como "naturais" e adverte contra os que as tomam como fenômenos universais.

Certamente, Sport, Sexualities and Queer/ Theory é uma obra de referência aos que desejam eleger a Teoria Queer e pensar suas possibilidades nos esportes. Nos capítulos apresentados na primeira parte ( $\mathrm{e} \| \mathrm{I})$, além de serem mais teóricos, há uma visível preocupação em contextualizar o debate sobre as teorias de gênero e as novas possibilidades de considerações da presença do sujeito não inteligível (queer) em âmbito social/esportivo. Já os quatro capítulos da parte II, sendo compêndios de pesquisas acadêmicas, figuram como tentativas de modelamento da teorização de gênero à realidade etnográfica. Assim, praticamente todas reafirmam que as normas de gênero da sociedade heteronormativa são reproduzidas e reafirmadas por atletas queer. Os últimos capítulos (parte III) não se alinham muito ao restante da obra, trazendo contribuições para pensar o corpo trans, a própria feminilidade lésbica e os processos de subjetivação relacionados à dor psíquica/física. Entretanto, ainda fica a questão: como executar uma subversão dos pressupostos do esporte convencional a partir das lógicas queer?

\section{Notas}

' Jayne Caudwell, na introdução, destaca que o conceito "queer" pode ser usado de muitas formas a fim de descrever ativismo, política, identidade, teoria e comunidade, e também pode aparecer como adjetivo, verbo ou substantivo.

${ }^{2}$ Título original: "Beyond the Pale: The Whiteness of Sport Studies and Queer Scholarship". Para a autora, a expressão beyond the pale tem duas referências importantes: "basta à dominação Pale" (Império britânico na Irlanda no século XIV); e "chega de branqueza", crítica feminista aos estudos de mulheres brancas, de classe média, educadas etc. Resolvi traduzir pela nossa expressão na língua portuguesa por "além da conta".

${ }^{3}$ Versão original: Loker room culture. 
${ }^{4} \mathrm{O}$ título original Ten men out diz respeito aos homens que fogem do 'esquema convencional', por assim dizer. Isso porque o softball é mais praticado por mulheres. No jogo de palavras, os atletas canadenses homens praticantes de tal modalidade estariam, então, "fora do esquema tradicional" do esporte.

${ }^{5}$ Brian PRONGER, 1990.

${ }^{6}$ PRONGER, 1990, p. IX.

${ }^{7}$ Exigiam laudo médico que atestasse "completa transição de gênero".

${ }^{8}$ Sem tradução plausível em português, catching crabs significaria um erro de má sincronia na canoagem.

${ }^{9}$ O tipo de relação a que se estabeleceu entre Owen e a equipe gay de canoagem é similar àquela assumida por Loïc Wacquant (2002) junto aos boxeadores do clube negro de Woodlawn e registrada em sua brilhante etnografia sobre o gym e as relações de rede estabelecidas em Chicago, nos anos 1990.

\section{Referências bibliográficas}

BUTLER, Judith. Problemas de gênero: feminismo e subversão da identidade. Rio de Janeiro: Civilização Brasileira, 2004.

FOUCAULT, Michel. História da sexualidade. A vontade de saber I. 8. ed. São Paulo: Graal, 1985.

PRONGER, Brian. The Arena of Masculinity: Sports, Homosexuality and the Meaning of Sex. New York: St. Martin's Press, 1990.

WACQUANT, Loïc. Corpo e alma: notas etnográficas de um aprendiz de boxe. Rio de Janeiro: Relume Dumará, 2002.

Wagner Xavier de Camargo Universidade Federal de Santa Catarina 